\title{
Phenol Contents and Antioxidant Activity of Sonokeling (Dalbergia latifolia Roxb) Wood
}

\author{
Masendra, Denny Irawati, Almaratush Shoolichah Ridlo, and Ganis Lukmandaru
}

\begin{abstract}
Dalbergia latifolia or sonokeling is a native species of Java, Indonesia, used as an important wood for furniture and building materials, due to the high of durability and beautiful color. This study, therefore, was aimed to investigate the phenol composition, represented by total phenolic, flavonoid, and flavanol content, as well as antioxidant activity, conducted by DPPH (1, 1-diphenyl-2-picrylhydrazyl) method on $D$. latifolia wood. The sample was extracted using ethanol-toluene solvent in a Soxhlet apparatus, and subsequently subjected to column chromatography. This treatment yielded 12 fractions, which were then evaluated for phenol contents and antioxidant activity. The results showed a high antioxidant activity and total phenolic content in Fr.1- Fr.3, while latifolin was detected and characterized by GC-MS and a literature comparison. Therefore, it was established that the antioxidant activity of $D$. latifolia wood extractives properly correlated with the total phenolic, but not with the total flavonoid and flavanol contents.
\end{abstract}

Keywords: Sonokeling, DPPH activity, phytomedicine, neoflavonoid, extractives

\section{Introduction}

Dalbergia latifolia called sonokeling (Javanese) or Java palisander (English) is a native species from Indonesia, known to possess beautiful wood, with a brown to dark brown color (Orwa et al. 2009). In addition, they are classified as highly resistant, naturally durable (Kalynasundaran and Ganti 1975), placed in strength class II (Dwianto et al. 2019), and also deliver good acoustical properties (Karlinasari et al. 2012). Hence, the wood is commonly used in the manufacture of furniture and building materials.

Based on the chemical properties, Sekine et al. (2009) isolated some neoflavonoids compounds from the heartwood, D. latifolia, characterized as latifolin and its derivatives, which were then tested for antitermite and antifungi activities (Sekine et al. 2009). The wood, bark, and leaves extracts were also reported to confer anticancer and antioxidant effect (Khalid et al. 2011; Niraimathi and Sundaraganapathy 2014; Liu et al. 2018; Tripathi 2018). Other investigations performed on the genus Dalbergia demonstrated the propensity for the leaf extract of $D$. saxatilis to increase kidney toxicity (Ismail et al. 2015), D. sisoo to function as a photoprotective and DNA protective agents (Yasmeen and Gupta 2016), while D. parviflora contained antioxidant isoflavonoids (Castellano and Torrens 2015).

This antioxidant activity is affiliated with the protection of cell body from free radicals continuously which is produced internally, where the excess quantities are responsible for various disease manifestations (Young and Woodside 2001). Numerous radicals are known to be highly reactive with other molecules, e.g., DPPH (1, 1-diphenyl-2picrylhydrazyl), which is unstable in dark purple color. Meanwhile, phenolic compounds as antioxidants play the role of donating proton to reduce DPPH-H to the nonradical form of DPPH, which is an activity of polyphenols from plants (Ku et al. 2007; Gan et al. 2010). This study, therefore, investigated the wood extractives obtained from $D$. latifolia wood, in order to determine the phenol contents and antioxidant activity.

\section{Materials and Methods}

\section{Sample Collection and Extraction}

The sample of $D$. latifolia wood was purchased and collected from a wooden industry in Bantul, Yogyakarta, Indonesia. The $10 \mathrm{~g}$ of the heartwood and sapwood were mixed and milled to powder, followed by drying at oven temperature $40^{\circ} \mathrm{C}$ for a week, and then extraction was conducted using ethanol-toluene $(2 / 1, v / v)$ in soxhlet apparatus for $6 \mathrm{~h}$.

\section{Column Chromatography and Gas Chromatography Mass Spectrometry (GC-MS) Analysis}

Si-gel 60 with size of 63-210 $\mu \mathrm{m}$ (Kanto Chemical Co., Inc., Japan) was used for column chromatography, where $n$ hexane, ethyl acetate (EtOAc), acetone, and methanol $(\mathrm{MeOH})$ were loaded as eluent. Conversely, a GC-MS-QP 2010 (Shimadzu, Japan) machine was implemented to detect the compound, as $1 \mu \mathrm{l}$ of the sample $(1 \mathrm{mg} / \mathrm{ml})$ was directly injected with column temperature from $100^{\circ} \mathrm{C}(1$ $\min )$ to $320^{\circ} \mathrm{C}$ at $5^{\circ} \mathrm{C} / \mathrm{min}$; while that for injection and detection were $250^{\circ} \mathrm{C}$ and $320^{\circ} \mathrm{C}$, respectively. In addition, DB-1 capillary column $(30 \mathrm{~m} \times 0.25 \mathrm{~mm}$ I.D. and $0.25 \mu \mathrm{m}$; GL Sciences, Tokyo, Japan) was used in the machine, using helium as the carrier gas, and the acquisition mass were set from 50-800 amu. Subsequently, the mass 
spectrum obtained for each sample was compared with data from the NIST library and the literature (Sekine et al. 2009).

\section{Total Phenolic Content (TPC)}

The Folin-Ciocalteu method by Diouf et al. (2009) was used as a reference during the investigation of TPC. Approximately $2.5 \mathrm{ml}$ of Folin-Ciocalteu phenol reagent (10 times dilution) was mixed with $0.5 \mathrm{ml}$ of the sample $(0.25$ $\mathrm{mg} / \mathrm{ml}$ ) and incubated for $2 \mathrm{~min}$, then $2 \mathrm{ml}$ of $7.5 \%$ aqueous sodium carbonate was added and incubated again for 30 min. Finally, the mixture was placed in the equipment, followed by the sample absorbance reading at $765 \mathrm{~nm}$, and the results of TPC were expressed as (+)- gallic acid equivalents (mg GAE/g extract).

\section{Total Flavonoid Content (TFC)}

TFC evaluation involved the $\mathrm{AlCl}_{3}$ method (Brighente et al. 2007), where $2 \mathrm{ml}$ of the sample prepared at $1 \mathrm{mg} / \mathrm{ml}$ concentration was reacted with $2 \% \mathrm{AlCl}_{3} .6 \mathrm{H}_{2} \mathrm{O}$ solution (2 $\mathrm{ml})$. This mixture was then incubated for $1 \mathrm{~h}$ at $20^{\circ} \mathrm{C}$, followed by the absorbance reading at $415 \mathrm{~nm}$, and the results expressed in quercetin equivalents (mg QE/g extract).

\section{Total Flavanol Content (TVC)}

The TVC was determined using the vanillin- $\mathrm{HCl}$ method (Richard et al. 1978), where $0.5 \mathrm{ml}$ of the sample (1 $\mathrm{mg} / \mathrm{ml}$ concentration) was mixed with $3 \mathrm{ml}$ of $4 \%$ vanillin reagent and $1.5 \mathrm{ml}$ of $\mathrm{HCl}$. This reaction was performed for $15 \mathrm{~min}$ at ambient temperature, followed by the absorbance reading at $500 \mathrm{~nm}$, and standard calibration used was of (+)catechin (mg CE/g extract).

\section{Determination of DPPH Radicals Scavenging Activity}

The determination of DPPH radicals scavenging or antioxidant activity was conducted according to Gao et al. (2006), where each $0.1 \mathrm{ml}$ methanolic extract at different concentrations were mixed with $5 \mathrm{ml}$ of $0.004 \% \mathrm{DPPH}$ in methanol and incubated for 30 minutes. Therefore, the sample absorbance was read at $517 \mathrm{~nm}$, using UV-Vis spectrophotometer, and the antioxidant activity was calculated using the following equation:

$$
\text { DPPH scavenged }(\%)=100 \times(\text { Ao-A1) } / \text { Ao }
$$

Where Ao is the absorbance of blank and $A 1$ is absorbance of sample. The antioxidant activity also was represented as $\mathrm{IC}_{50}$, which is an expression for the concentration responsible for inhibiting $50 \%$ activity.

\section{Chemicals}

(+)- Gallic acid (97.5\%), (+)- catechin ( $\geq 95 \%)$, quercetin $(\geq 95 \%)$, and 1,1-diphenyl-2-picrylhydrazyl were purchased from Sigma Aldrich (Germany), while heneicosane $(\geq 95 \%)$ was obtained from Kanto Chemical Co., Inc. (Tokyo, Japan).

\section{Results and Discussion}

\section{Extraction and Isolation}

The yield of $D$. latifolia ethanol-toluene extract was not mentioned in this report, although Table 1 shows the result of sample fractionation. Conversely, the isolation process involved the use of column chromatography with $n$-hexane as solvent, whose polarity was increased with EtOAc, acetone, $\mathrm{MeOH}$, and water. At the inception, Fr. 1 and Fr. 2 had the highest yield of $0.74 \mathrm{~g}$ and $0.34 \mathrm{~g}$ (Table 1), which were collected in the eluent of $n$-hexane $100 \%$ and $n$ hexane/EtOAc 80\%, respectively. Therefore, it is established that $D$. latifolia wood extractives is dominated by apolar compounds, although Fr. 12 yielded $0.59 \mathrm{~g}$ in the $\mathrm{MeOH}$-water soluble fraction (polar compounds). This fraction is observed to possess a comparably higher content, and predicted to comprise of more polar components, including tannins.

\section{Characterization of Fr.1- Fr.12}

The 12 fractions were analyzed using GC-MS by direct injection, where only Fr. 1, Fr. 2, and Fr. 3 demonstrated a compound with a higher peak at a similar retention time of 41.5 mins (Figure 1), suggesting the tendency of similar components. Meanwhile, none was detected from Fr. 4- Fr. 12, as the presence of polar compounds possibly requires further processing by silylation or methylation.

Further discussions were performed to characterize Fr. 1- Fr. 3, through a comparison with the mass spectra of latifolin, as demonstrated in Table 2. Furthermore, the molecular weight obtained for Fr. 1- Fr. 3 was at m/z 286, alongside a base relative intensity at $\mathrm{m} / \mathrm{z} 154$. Therefore, a similarity was established between the fragmentations and latifolin, as reported by Sekine et al. (2009), making it the main compound, based on literature comparisons. This was also demonstrated in previous investigations performed on the genus Dalbergia, as an isolate from $D$. parviflora (Muangnoicharoen and Frahm 1982), with the molecular structure displayed in Figure 2. 
Table 1. Yield of fractionation of $D$. latifolia wood

Column chromatography of ethanol toluene fraction $(3.39 \mathrm{~g})$

\begin{tabular}{lcc}
\hline Eluting solvents & Fraction number & Weight (g) \\
\hline$n$-Hexane & 1 & 0.74 \\
$n$-Hexane-EtOAc (8/2) & 2 & 0.34 \\
$n$-Hexane- EtOAc (7/3) & 3 & 0.08 \\
$n$-Hexane- EtOAc (5/5) & 4 & 0.30 \\
$n$-Hexane- EtOAc (3/7) & 5 & 0.20 \\
$n$-Hexane- EtOAc (2/8) & 6 & 0.18 \\
$n$-Hexane- EtOAc (1/9) & 7 & 0.08 \\
EtOAc & 8 & 0.09 \\
EtOAc -acetone (5/5) & 9 & 0.19 \\
Acetone & 10 & 0.06 \\
MeOH & 11 & 0.43 \\
MeOH- water (1/1) & 12 & 0.59 \\
\hline Total & & 3.28
\end{tabular}

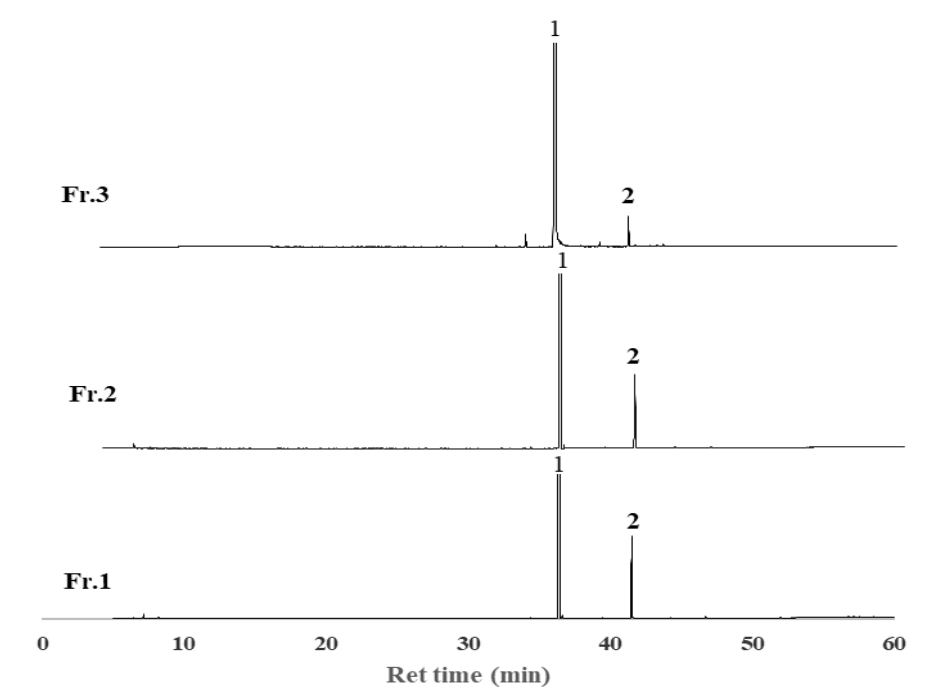

Figure 1. Chromatograms of GC- MS from Fr. 1- Fr. 3; 1. Heneicosane (Internal Standard (retention time: 36.4 min)), 2. Targeted compound (ret. time: $41.5 \mathrm{~min}$ ) of Dalbergia latifolia wood 
Table. 2. Comparison mass spectra of latifolin with Fr.1- Fr.3 of Dalbergia latifolia wood

\begin{tabular}{lc}
\hline Samples & \multicolumn{1}{c}{ Mass spectra fragmentations } \\
\hline $\begin{array}{l}R-(-)- \\
\text { latifolina }\end{array}$ & $286[M]^{+}(47), 269(4), 255(25), 240(3), 227(3), 211(4), 193(2), 180(9), 167(12), 154(100), 139(16)$, \\
& $133(13), 131(13), 115(10), 107(12), 105(6), 91(7), 77(13), 69(15), 65(7), 51(8)$ \\
Fr. 1 & $\begin{array}{l}286[M]^{+}(83), 269(7), 255(42), 240(5), 227(4), 211(6), 193(3), 180(9), 167(11), 154(100), 139(19), \\
\end{array}$ \\
Fr. 2 & $283(18), 131(18), 115(14), 107(19), 105(10), 91(14), 77(22), 69(21), 65(10), 51(10)$ \\
& $133(18), 131(18), 115(14), 107(20), 105(10), 91(13), 77(22), 69(19), 65(10), 51(9)$ \\
& \\
Fr. 3 & $286[M]^{+}(86), 269(7), 255(40), 240(7), 227(7), 211(7), 193(3), 180(9), 167(10), 154(100), 139(17)$, \\
\end{tabular}

(a): Sekine et al. 2009

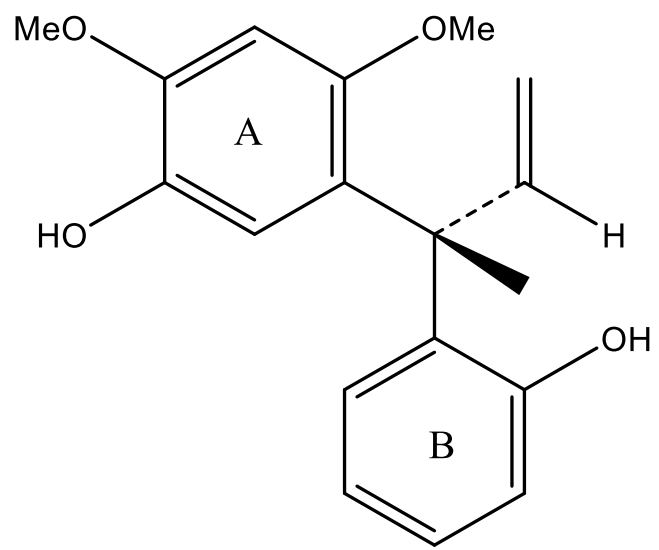

Figure 2. Chemical structure of $R$ - (-)- latifolin from $D$. latifolia

\section{Phenol Contents and Antioxidant Activity}

The phenol content and antioxidant activity of Fr. 1- Fr. 12 were displayed in Table 3, as the highest TPC concentration was observed in Fr. 1 and Fr. 2, while Fr. 1 and Fr. 4 demonstrated the most significant level of TFC, and high TVC values were identified in Fr. 7 and Fr. 9. A comparison with previous works showed a markedly lower amount of TPC, especially in the Fr. $1(469.8 \mathrm{mg} / \mathrm{g})$ and Fr. $2(415.5 \mathrm{mg} / \mathrm{g})$, than in the bark of $D$. latifolia at $641.8 \mathrm{mg} / \mathrm{g}$ (Khalid et al. 2011), although higher than reported by Tripathi (2018) in the leaves $(29.1 \mathrm{mg} / \mathrm{g})$. Conversely, the TFC value for Fr. 1 (171.6 mg/g), Fr. 4 (173.2 mg/g), and Fr.
$9(170.5 \mathrm{mg} / \mathrm{g})$ were higher than previous reports on the bark of $D$. latifolia, at $46 \mu \mathrm{g} / \mathrm{ml}$ (Khalid et al. 2011).

The test conducted with DPPH demonstrated a higher level of antioxidant activity in Fr. 1- Fr. 3 (Table 3), which was affiliated with the presence of latifolin as the main compound. Therefore, the high values in these fractions were assumed to have been affected by the neoflavonoids, despite the comparably higher level of the positive control, encompassing cathecin, quercetin, and gallic acid. This study also demonstrated lower antioxidant activity in Fr. 1Fr. 3 when compared to the bark of $D$. latifolia (Khalid et al. 2011). However, the values recorded were higher than $D$. saxatilis woody roots (Isyaka et al. 2015). 
Table 3. Total phenolic content, total flavanoid, and antioxidant activity of fractions of $D$. latifolia wood

\begin{tabular}{|c|c|c|c|c|c|c|}
\hline \multirow{2}{*}{ Fraction } & \multirow{2}{*}{$\mathrm{TPC}^{\mathrm{a}}$} & \multirow{2}{*}{$\mathrm{TFC}^{\mathrm{b}}$} & \multirow{2}{*}{ TVCc } & \multicolumn{2}{|c|}{ DPPH scavenging activity (\%) } & \multirow{2}{*}{$\begin{array}{c}\text { IC50 } \\
(\mu \mathrm{g} / \mathrm{ml})\end{array}$} \\
\hline & & & & $500 \mu \mathrm{g} / \mathrm{ml}$ & $250 \mu \mathrm{g} / \mathrm{ml}$ & \\
\hline Fr. 1 & 469.8 & 171.6 & 28.3 & 72.2 & 37.6 & 340.4 \\
\hline Fr. 2 & 415.5 & 128.4 & 28.8 & 82.0 & 41.7 & 303.3 \\
\hline Fr. 3 & 191.3 & 144.4 & 52.8 & 59.6 & 26.8 & 393.1 \\
\hline Fr. 4 & 187.4 & 173.2 & 48.4 & 40.8 & 23.2 & 663.8 \\
\hline Fr. 5 & 82.2 & 101.1 & 31.8 & 24.5 & 13.8 & 1179.2 \\
\hline Fr. 6 & 109.0 & 166.4 & 54.0 & 31.0 & 15.8 & 7848.0 \\
\hline Fr. 7 & 113.3 & 162.4 & 61.6 & 28.0 & 15.6 & 1041.4 \\
\hline Fr. 8 & 128.8 & 158.8 & 52.1 & 28.1 & 12.1 & 944.9 \\
\hline Fr.9 & 142.8 & 170.5 & 56.8 & 37.3 & 21.9 & 592.0 \\
\hline Fr. 10 & 152.1 & 97.1 & 44.9 & 41.9 & 26.4 & 604.6 \\
\hline Fr. 11 & 69.0 & 96.6 & 8.3 & 26.0 & 6.7 & 1110.5 \\
\hline Fr. 12 & 51.6 & 104.7 & 31.4 & 20.4 & 11.3 & 1328.4 \\
\hline Catechin & - & - & - & 93.8 & 92.0 & 83.3 \\
\hline Quercetin & - & - & - & 96.1 & 93.0 & 28.7 \\
\hline Gallic acid & - & - & - & 94.6 & 94.5 & 88.5 \\
\hline
\end{tabular}

(-): not determined, DPPH: 1,1-diphenyl-2-picrylhydrazyl

aDetermined by Folin-Ciocalteu assay, in units of milligrams (+)-gallic acid equivalent per gram sample

bDetermined by $\mathrm{AlCl}_{3}$ assay, in units of milligrams quercetin equivalent per gram sample

'Determined by vanillin- $\mathrm{HCl}$ assay, in units of milligrams $(+)$-catechin equivalent per gram sample

\section{Correlation between Phenol Contents and Antioxidant Activity}

Figure 3 shows the plots between antioxidant activity and phenol contents, which displayed a good pattern against TPC, suggesting the dependence of $D$. latifolia on TPC for effectiveness (3a), while Figure $3 b$ and $3 c$ were resulted in random plots. This relationship is in agreement with several prior studies (Eddebbagh et al. 2016; Guedes et al. 2017; Amamra et al. 2018; Hossain et al. 2019).

The measurement of TPC indicates the presence of phenols, hence a better understanding of the particular compound responsible in the antioxidant activity requires the conduction of specific phenol evaluation, through TFC and TVC. Figure $3 \mathrm{~b}$ showed a low correlation with TFC, although fractions demonstrating high effectivity were generally observed to possess high concentrations. Furthermore, GC-MS data in the current study and a previous work (Sekine et al. 2009) reported on the presence of neoflavonoids on the extracts of $D$. latifolia, as the common fractions with more significant activity also possessed higher total flavonoids. The neoflavonoids identified in this research, including latifolin probably does not refer to the total flavonoids measured by the unit of standard, quercetin (Figure 4a). Based on the analysis of regression, the direct correlation against TFC was also weak, which is inconsistent with the previous reports by Eddebbagh et al. (2016) and Amamra et al. (2018), although in agreement with the study by Ghasemi et al. (2009) on peels and tissues of 13 citrus species.

Further determination on more specific phenols was also conducted for TVCs, and the values obtained correlated properly with antioxidant activities (Figure 3c). Similar with TFC, it was impossible to establish a good correlation against TVC, due on the generally opposing values recorded, as shown in Table 3 . This outcome suggests the weak dependence of antioxidant activity on TVC, which was expressed in catechin unit, possessing latifolin as the main compound and a different type flavonoid. Conversely, flavanols or catechins are flavanones 3-hydroxy derivatives, also referred to as flavan-3-ols, due to the bound of the hydroxyl group with the $C$ ring at position 3 (Figure 4b). This compound is classified as a neoflavonoid, possessing the 4-phenylchromone skeleton, which is different from the 2-phenylchromen-4-one backbone (Phance et al. 2016). The varying concentration of catechins and latifolin as the main compounds in $D$. latifolia wood possibly lead to the reduced value of TVC in Fr. 1- Fr. 12, and is also associated with the absence of a good correlation against antioxidant activity. Meanwhile, the flavanols responsible for the donation of proton in the sample were not detected, which is different from the study of Henning et al. (2003) conducted on green tea extract, but in agreement with the research on tea extracts by Gao et al. (2013). 


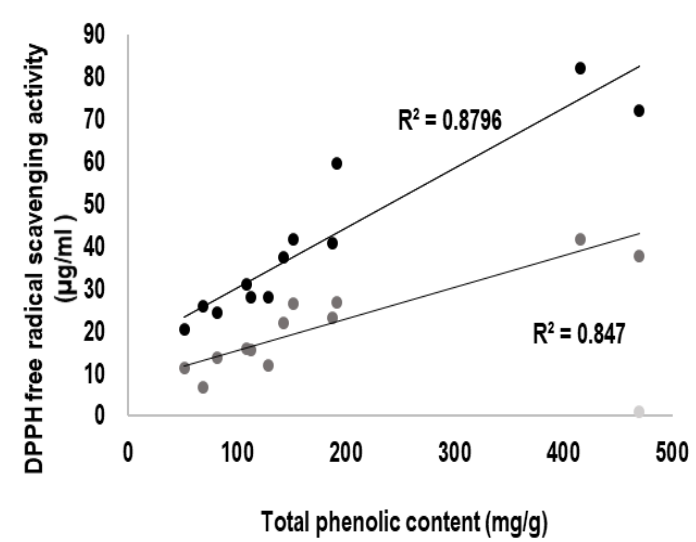

(a)

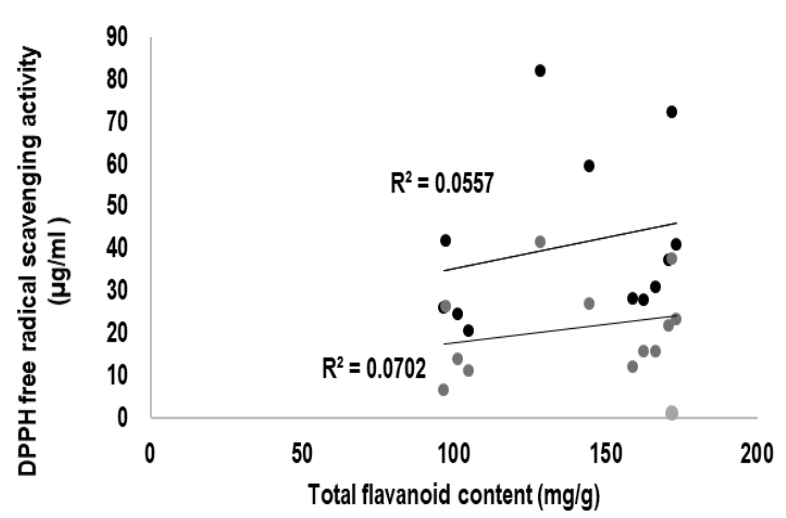

(b)

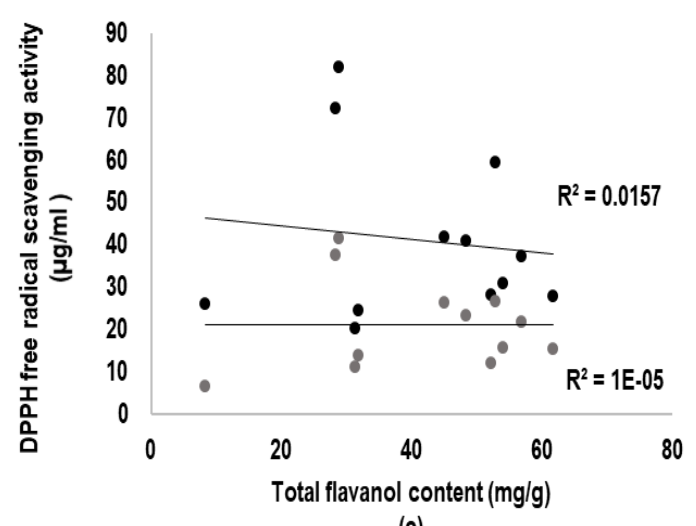

(c)

Figure 3. Correlation between antioxidant activity and total phenolic content (a), total flavonoid content (b), and total flavanol content (c). Black circles, $500 \mu \mathrm{g} / \mathrm{ml}$; gray circles, $250 \mu \mathrm{g} / \mathrm{ml}$ of Dalbergia latifolia.<smiles>O=c1c(O)c(-c2ccc(O)c(O)c2)oc2cc(O)ccc12</smiles>

(a)<smiles>Oc1cc(O)c2c(c1)O[C@H](c1ccc(O)c(O)c1)[C@H](O)C2</smiles>

(b)

Figure 4. Common chemical structure of quercetin (a) and catechin (b).

\section{Conclusions}

Based on the results and discussion, it was established that Fr. 1- Fr. 3 showed comparably higher TPC and antioxidant activity than other fractions. Conversely, more significant levels of TFC were observed in Fr. 1 and Fr. 4, while Fr. 7 and Fr. 9 demonstrated relatively better TVC concentrations. The GC-MS analysis detected latifolin in Fr. 1- Fr. 3, which was assumed to be responsible for antioxidant activity. Furthermore, the differences observed in the results of correlation against TPC, TFC, and TVC suggests the dependence of $D$. latifolia wood on TPC for effectiveness. 


\section{References}

Amamra, S.; M.E. Cartea; O.E. Belhaddad; P. Soengas; A. Baghiani; I. Kaabi; L. Arrar. 2018. Determination of Total Phenolics Contents, Antioxidant Capacity of Thymus vulgaris Extracts Using Electrochemical and Spectrophotometric Methods. International Journal of Electrochemical Science 13(8): 7882- 7893.

Brighente, I.M.C.; M. Dias; L.G. Verdi; M.G. Pizzolatti. 2007. Antioxidant Activity and Total Phenolic Content of Some Brazilian Species. Pharmaceutical Biology 45(2): 156-161.

Castellano, G.; F. Torrens. 2015. Quantitative Structureantioxidant Activity Models of Isoflavonoids: A theoretical Study. International Journal of Molecular Science 16(6): 12891-12906.

Diouf, P.N.; T. Stevanovic; A. Cloutier. 2009. Antioxidant Properties and Polyphenol Contents of Trembling Aspen Bark Extracts. Wood Science and Technology 43(5): 457-470.

Dwianto, W.; A. Bahanawan; S.S. Kusumah; T. Darmawan; Y. Amin; D.A. Pramasari; E. Lestari; F. Akbar; Sudarmanto. 2019. Study on the Existence and Characteristics of Sonokeling (Dalbergia latifolia Roxb) as An Appendix II CITES Wood. The 8th International Symposium for Sustainable Humanosphere. IOP Conf. Series: Earth and Environmental Science 374012063.

Eddebbagh, M.; M. Messaoudi; A. Abourriche; M. Berrada; M. Attaleb; L. Benbacer; A. Bennamara. 2016. Correlation of the Cytotoxic and Antioxidant Activities of Moroccan Pomegranate (Punica Granatum) with Phenolic and Flavonoid Contents. Journal of Pharmacy and Pharmacology 68(4): 511-119.

Gan, R.Y.; X.R. Xu; F.L. Song; L. Kuang; H.B. Li. 2010. Antioxidant Activity and Total Phenolic Content of Medicinal Plants Associated with Prevention and Treatment of Cardiovascular and Cerebrovascular Diseases. Journal of Medicinal Plants Research 4(22): 2438-2444.

Gao, H.; T.F. Shupe; C.Y. Hse; T.L. Eberhardt. 2006. Antioxidant Activity of Extracts from the Bark of Chamaecyparis Lawsoniana (A. Murray) Parl. Holzforschung 60(4): 459- 462.

Gao, Y.P; D.S. Tang; S.Y. Gong. 2013. Study on the Relationship Between Tea Antioxidant Activity and Tea Polyphenols and Catechins. Journal of Chinese Institute of Food Science and Technology 13(2): 40-47.

Ghasemi, K.; Y. Ghasemi,; M.A. Ebrahimzadeh, 2009: Antioxidant Activity, Phenol and Flavanoid Contents of 13 Citrus Species Peels and Tissues. Pakistan Journal of Pharmaceutical Sciences 22(3): 277- 281.

Guedes, M.N.S.; R. Pio; L.A.C. Maro; F.F. Lage; M.P.D.A. Abreu; A.A. Saczk. 2017. Antioxidant Activity and Total Phenol Content of Blackberries Cultivated in a Highland Tropical Climate. Acta Scientiarum 39(1): 4348.
Henning, S.M.; C. Fajardo-Lira; H.W. Lee; A.A. Youssefian; V.L.W. Go; D. Heber. 2003. Catechin of 18 Teas and a Green Tea Extract Supplement Correlates with Antioxidant Capacity. Nutrition and Cancer 4(2): 226235.

Hossain, M.A.; A.M. Weli; S.H.J. AhmedS. 2019. Comparison of Total Phenols, Flavonoids and Antioxidant Activity of Various Crude Extracts of Hyoscyamus Gaagheri Traditionally Used for Treatment of Epilepsy. Clinical Phytoscience 5(20): 18.

Ismail, H.F.; Z.A. Umar; D.U. Habib; Y.A. Hamza. 2015. Effect of Methanol Leaf Extract of Dalbergia saxatilis Hook. F (fabeceae) on Renal Function. Avicena Journal of Medicine 6 (6): 592-596.

Isyaka, M.S.; Y. Rufai; Y.H. Ishaq; A.C. Kendeson; A. Lukman. 2015. Antioxidant Activity of the Wood of Dalbergia saxatilis Hook $F$. Using UV/visible Spectrophotometer. Jewel Journal of Scientific Research 3(1): 88-93.

Kalynasundaran, N.; S.S. Ganti. 1975. Investigations on the Natural Durability of Indigenous Timbers for Use in Marine Construction. Journal of the Timber Development Association (India) 21(2): 15-26.

Karlinasari, L.; H. Baihaqi; A. Maddu; T.R. Mardikanto. 2012. The Acoustical Properties of Indonesian Hardwood Species. Makara Journal Science 16 (2): 110-114.

Khalid, M.; H.H. Siddiqui; S. Freed. 2011. In-vitro Assessment of Antioxidant Activity of Dalbergia latifolia Barks Extract Against Free Radicals. American-Eurasian Journal of Scientific Research 6 (3): 172-177.

Ku, C. S.; J.P. Jang; S.P. Mun. 2007. Exploitation of Polyphenol-rich Pine Barks for Antioxidant Activity. Journal of Wood Science 53(6): 524-528.

Liu, R.H.; D.Y. Mei; S. Lin; D.Q. Wang; F. Shao; L.Y. Chen; S.L. Guo. 2018. A New Benzofuran from the Heartwood of Dalbergia latifolia. Natural Product Research 33 (1): 47- 52.

Muangnoicharoen, N.; A.W. Frahm. 1982. Neoflavlanoids of Dalbergia parviflora. Phytochemistry 21(3): 767-772.

Niraimathi, V.; R. Sundaraganapathy. 2014. In Vitro Anti Cancer Activity of Various Fractions of Hydro Alcoholic Extract of $D$. latifolia Roxb. International Journal of Phytopharmacology 5(4): 272-83.

Orwa, C.; A. Mutua; R. Kindt; R. Jamnadass; A. Simons. 2009. Agroforestree Database: A Tree Reference and Selection Guide Version 4.0.

http://www.worldagroforestry.org/sites/treedbs/treedat abases.asp.

Panche, A.N.; A.D. Diwan; S.R. Chandra. 2016. Flavonoids: An Overview. Journal of Nutritional Science 5(47): 115.

Richard, T., Broadhurst, B., Willian, J. T. 1978. "Analysis of Condensed Tannins Using Acidified Vanillin". Journal of the Science of Food and Agriculture 29: 788-94. 
Sekine N., Ashitani T., Murayama T., Shibutani S., Hattori S., Takahashi K. 2009. Bioactivity of Latifolin and Its Derivatives Against Termites and Fungi. Journal of Agriculture Food Chemistry 57: 5707-5712.

Tripathi, R. 2018. In Vitro A-Glucosidase Inhibitory Potential and Free Radical Quenching Activity of Some Selected Medicinal Plants Total Poly Phenolic Content and Its Pharmacological Activity of Medicinal Plant. Journal of Emerging Technologies and Innovative Research 5(7): 538- 548.

Yasmeen, S.; P. Gupta. 2016. Invitro Demonstration of Dalbergia sissoo (Indian Rosewood) Methanolic Extracts as Potential Agents for Sunscreening and DNA nick Prevention. International Journal of Pharmacy and Pharmacheutical Sciences 8 (6): 17581.
Young, I.S.; J.V. Woodside. 2001. Antioxidants in Health and Disease. Journal of Clinical Pathology 54: 176186.

Masendra, Denny Irawati, Almaratush Shoolichah Ridlo, and Ganis Lukmandaru

Department of Forest Products Technology, Faculty of Forestry, Universitas Gadjah Mada,

Jl. Agro No.1, Bulaksumur, Yogyakarta 55281, Indonesia.

Tel. and Fax. : : +6274 550541

E-mail : glukmandaru@ugm.ac.id 